\title{
Impact of group music therapy on the depression mood of college students*
}

\author{
Jinliang Wang ${ }^{1}$, Haizhen Wang ${ }^{2}$, Dajun Zhang ${ }^{1}$ \\ ${ }^{1}$ Center for Mental Health Education, Southwest University, Chongqing, China; \\ *Corresponding Author: zhangdj@swu.edu.cn; \\ ${ }^{2}$ School of Public Administration, Chongqing Youth Vocational and Technical College, Chongqing, China.
}

Received 25 December 2010; revised 31 January 2011; accepted 28 February 2011.

\begin{abstract}
The goal of this study was to examine the effects of group music therapy on depression and mental health among college students. 80 students participated in this study, with 40 assigned to control group and other 40 assigned to experimental group. The results showed that after the group music therapy, for the experimental group, the depression scores have reduced significantly and the mental health scores have improved, while for the control group, no significant difference was obtained on the depression and mental health scores. This indicates that group music therapy can effectively reduce depression and improve mental health.
\end{abstract}

Keywords: Group Music Therapy; College Students; Depression; Mental Health

\section{INTRODUCTION}

Mental health problems, which are featured by the disturbance and disorder of mental and psychological activities, refer to the undesirable psychological factors or psychological states that affect the normal behavior and activity efficacy of individuals. As a special group that undertakes the high expectation from the society and parents, college students are obviously under more psychological pressure than other peer groups. A review on previous investigations about college students' mental problems showed that college students suffer from different types of psychological problems, especially depression, anxiety, somatization, and interpersonal sensitivity [1-3]. Depression ranks the top among these mental problems that disturb college students in the order of seriousness. Therefore, this study chose depression as

*This study was supported by the fund of Key Project 'Strategies on Cultivating College and Middle School Students' Personality Traits' at Key Humanity Social Science Research Institute in Chongqing. the target of intervention of group music therapy. In the mean time, the impact of group music therapy on depression and overall mental health of college students was also explored.

According to previous research on college students' depressive symptoms, depression may be closely relate to various life events and individuals' ways of coping with these psychological stimuli [4]. For instance, social competition, academic pressure, interpersonal communication pressure, quarrelling with others, serious defeat, being not smooth or being disappointed in love, and disordered close family relationship can contribute to the depressive symptoms of college students. Among these reasons, negative coping method, health adaptation factor, active coping methods, punishment and study pressure have most impact on depressive symptoms [5]. Research also showed that individual variables are important to depression, such as high sensitivity to loss and being overlooked, low self-esteem, difficulty in admitting and mobilizing the emotions, intrapsychic conflict caused by dependence, frequent bouts of tension, and long exposure to depression-induction environment. An effective intervention can be designed then the above factors are fully considered.

Since 1980s, researchers have conducted interventions on reducing depressive symptoms of college students, which involved combination of hypnosis and relaxation training, reading, physical exercises like Chinese shadowboxing and body-building exercises, offering courses in mental hygiene and personality psychology, and laying emphasis on social and family support. Music therapy, as an important means of intervention on depression, has been shown to be effective in reducing depression mood [6-9].

An inspection on literature showed that some effective means of intervention into depressive symptoms of college students are applied from the perspectives of cognition, will, behavior, and society, which involve change of cognition, tempering of will, enhancement of behavior, 
and adaptation to society. Zhang points out that current mental health education inclines to "highlighting behavior training while overlooking the internalization of experiences” during specific practice. Therefore, the important role of internalization of emotion and experiences shall be emphasized properly [10]. According to the analysis on the literature, depressive symptoms are a type of sad emotion experienced by the individual, with subjective negative emotional experience as its core element. Therefore, the key to reducing depressive symptoms is to transfer the negative emotional experience into positive emotional one. In the above studies of effective methods to affect depressive symptoms of college students, we find little of study on effective intervention from the perspective of emotional experience. Hence, this study tries to use music therapy as the intervention to decrease the depressive symptoms of college students. It is an exploratory study on the mental health education of college students. In the current study, two hypotheses were proposed.

Hypothesis 1. Music therapy may effectively affect the depressive symptoms of college students.

Hypothesis 2. Music therapy may promote the overall mental health of college students by alleviating the depressive symptoms.

\section{METHOD}

\subsection{Participants}

Tests of depressive symptoms and overall mental health have been conducted for the participants selection. According to the study of $\mathrm{Wu}$ [11] and $\mathrm{Ji}$, et al [12], the college students with the score of SDS self-rating depression scale, greater than 40 and score of depression factors of SCL-90, the symptom checklist, greater than 2.18 are selected as the participants. In this study, 80 students (Control group $=40$, Experimental group $=40$ ) were selected as the participants (Mean age $=19.35$; SD $=1.68)$.

\subsection{Experimental Design}

The balance group pre-test and post-test experimental design is used, with the music therapy as the independent variable and the depression score and mental health score as the dependent variable (See Table 1).

\subsection{Measurement}

The self-rating depressive scale (SDS) The Chinese version of the SDS is a self-report measure of depression consisting of 20 items, with a four-point scale ranging from a little of the time (1) to most of the time (4). Of the 20 items, 10 are worded positively and 10 are worded
Table 1. Experimental design of music therapy intervention on depression.

\begin{tabular}{cccc}
\hline Group & Pre-Test & Intervention & Post-Test \\
\hline \multirow{3}{*}{ Experimental } & Depression & & Depression \\
group & score & Music therapy & score \\
& Mental & & Mental \\
& health score & & health score \\
& Depression & & Depression \\
Control group & score & \multirow{2}{*}{ No therapy } & score \\
& Mental & & Mental \\
& health score & & health score \\
\hline
\end{tabular}

negatively. The former 10 items are reversed items [13]. The validity and the reliability of the SDS have been reported (for review, see Zung, 1986) [14].

The symptom checklist 90 (SCL-90) The Chinese version of the SCL-90 was used to measure mental health level of the participants. The 90 -item scale includes 10 factors including somatization, obsessivecompulsive symptoms, interpersonal sensitivity, depression, anxiety, hostility, phobia anxiety, paranoia ideation, psychoticism, et al. The validity and the reliability of the SCL-90 have been reported (Derogatis, 1984) [15].

\subsection{Intervention}

The entire intervention was divided into 3 stages including the introduction stage, the implementation stage, and the feedback stage, with each stage having their own themes. Specifically, the introduction stage has one theme: cultivating and training interpersonal skills. Students suffering from depression tend to withdraw from group activities because they feel inferior, lack experiences or have no common interests and often do not know how to build relationship with others. Music therapy activity, however, can help them interact with one another and provide them with the opportunity and motivation for participating group activity. In the stage two (namely the implementation stage), five themes are included, which are relaxation training, attention training, rhythm and movement training, music-painting training, and adaptative cognition training. We have good reasons to select these themes as our intervention focuses. For example, for participants who suffer from anorexia, insomnia, tension, fidget and mood swings, it is difficult to calm them down to appreciate music, so relaxation training is conducted, i.e. training on how to loose all muscles or to take deep breathing to alleviate their tension or fidget and then they are guided to appreciate music. Attention training is to mobilize potentials of the participants fully and for bringing their other healthy psychological factors into normal function. Rhythm and movement training is to help participants rebuild their adaptive behavior. Music- 
painting is to make the individual draw the sound he or she wants to voice out on a piece of paper, or make him or her paint on a piece of paper what he or she feels from listening to the music. Adaptative cognition training is to help them learn how to cognize and evaluate things with reasonable way in a positive mood. After each theme, a group discussion was held for participants to write their achievements or gains in the activity according to their actual situation. In the third stage (namely the conclusion stage), we focused on summary and feedback of intervention activities. Through the design of a farewell party, participants were reminded of the positive and unforgettable scenes in the activity and knew how to apply what they have learned in their future life and study.

\section{RESULTS}

An independent sample $t$ test was carried out to examine the difference in the depression score between the experimental group and the control group, and a matched sample $t$ test was run on the experimental group and the control group respectively to examine the difference in the depression scores between the pre-test and post-test. The results can be seen in Table 2 .

Table 2 shows that there was no significant difference in the depression scores between the two groups before the experiment $(t=-0.20, p>0.05)$. After the music therapy, however, significant difference was obtained between the experimental group and control group ( $t=$ $-5.13, p<0.001$ ), with the score of the experimental group lower than that of the control group. For the experimental group, we found a significant difference on the depression score between the pre-test and the posttest $(t=6.93, p<0.001)$. For the control group, however, we did not find any difference between the pre-test and post-test $(t=1.51, p>0.05)$.

An independent sample $t$ test was carried out to examine the difference in the mental health score between the experimental group and the control group, and a matched sample $t$ test was run on the experimental group and the control group respectively to examine the difference in the mental health score between the pre-test and post-test. The results can be seen in Table 3 .

Table 2. Difference between pre-test and post-test of depression scores in experimental group $(n=40)$ and control group (n $=40)$.

\begin{tabular}{lccc}
\hline \multirow{2}{*}{ Group } & Pre-test & Post-test & \multirow{2}{*}{$t$} \\
\cline { 2 - 3 } & $M \pm S D$ & $M \pm S D$ & \\
\hline Experimental group & $45.45 \pm 5.23$ & $40.21 \pm 5.10$ & $6.93^{* * *}$ \\
Control group & $46.01 \pm 5.34$ & $46.19 \pm 5.07$ & 1.51 \\
$t$ & -.20 & $-5.13^{* * *}$ & \\
\hline
\end{tabular}

Note: ${ }^{*} p<0.05 ; * * p<0.01 ; * * * p<0.001$
Table 3. Difference between pre-test and post-test of mental health scores between experimental group $(n=40)$ and control group $(n=40)$.

\begin{tabular}{lccc}
\hline \multirow{2}{*}{ Group } & Pre-Test & Post-Test & \multirow{2}{*}{$t$} \\
\cline { 2 - 3 } & $M \pm S D$ & $M \pm S D$ & \\
\hline $\begin{array}{l}\text { Experimental } \\
\text { group }\end{array}$ & $214.32 \pm 39.24$ & $198.73 \pm 44.11$ & $5.03^{* * *}$ \\
Control group & $213.35 \pm 38.93$ & $214.83 \pm 45.39$ & .26 \\
$t$ & 1.21 & $5.32^{* * *}$ & \\
\hline
\end{tabular}

Note: ${ }^{*} p<0.05 ; * * p<0.01 ; * * * p<0.001$

Table 3 showed that there was no significant difference in the mental health scores between the experimental group and control group in the pre-test $(t=1.21, p>$ 0.05). However, after the musical therapy, we found a significant difference in the mental health scores between the experimental group and the control group ( $t=$ 5.32, $p<0.001$ ), with the score of experimental group higher than that of control group. A significant difference between the pre-test and post-test was obtained for the experimental group ( $t=5.03, p<0.001$ ), while no significant difference between the pre-test and post-test was obtained for the control group $(t=0.26, p<0.05)$.

\section{DISCUSSIONS}

The purpose of this study was to explore whether group music therapy can reduce college students' depression and improve their mental health level. Our study found that there was no significant difference in the depression scores of the participants in the two groups before the intervention. However, after the musical therapy, the depression scores of the experimental group participants reduced significantly, while there was no significant difference between the pre-test and post-test for the control group. This finding is in line with previous studies, which found that group music therapy have significant effects on depression mood [16-18].This indicates that music therapy is effective in ameliorating the depression mood among college students, and our first hypothesis is supported.

Our study found that there was no significant difference in the mental health scores between the experimental group and control group before the intervention. However, after the intervention, a significant difference between the pre-test and post-test was obtained for the experimental group, while no significant difference between the pre-test and post-test was obtained for the control group. This indicates that, music therapy, through amelioration of the depressive symptoms of the participants in the experimental group, improves the overall mental health of the participants in the experimental 
group and realizes another purpose of the experiment. Our finding is in consistent with previous research showing that music therapy can improve mental health [19-20] and our second hypothesis is supported.

The reason that music therapy can effectively reduce depression and improve mental health can be summarized as the following. First, the design of the intervention in this study was well-directed, standardized and operatable. Combining the music selection, the arrangement in activity stage and arrangement in the appreciation process with the specific presentation of the college students' depressive symptom meets their psychological needs. Music therapy and group counselling technique were introduced into the intervention to train and cultivate the college students' ability to ameliorate depressive symptoms as well as to improve their overall mental health; meanwhile, their music aesthetic appreciation ability as well as their ability to communicate and cooperate with the others are also trained and cultivated. Finally, these abilities will be generalized and transferred into their daily life. The introduction of music therapy and group counseling technique helps this activity's operational plan to be more well-directed and operatable, and then improves the implementation practicability of the music aesthetic appreciation.

Moreover, the participants' feedback to the implementation of the music aesthetic appreciation intervention showed that participants' response to the presentation of music aesthetic appreciation activity and process operation was generally good and they were satisfied with the experiment as a whole. In the presentation of music aesthetic factors, experience aesthetic principle for the ways of music aesthetic appreciation, aesthetic characteristic of the music aesthetic appreciation environment in aspect of acoustic sense and aesthetic standards for guiding music aesthetic appreciation are the best embodiments. In the psychological process of music aesthetic, activities in each stage and process are implemented well.

\section{CONCLUSIONS}

Music therapy can effectively reduce college students depression symptoms;

Music therapy can significantly improve mental health level among college students.

\section{REFERENCES}

[1] Liu, M.J. and Yu, H. (1995) A study of the SCL-90 test result of college students. Psychological Science, 18, 295-298.

[2] Ji, H. (1999) An investigatory study on the psychological sushi of the undergraduates in teacher universities and suicidal crisis intervention. Journal of
Beijing Normal University (Social Sciences), 1, 26-33.

[3] Wen, H., Li, X. and Ge, J.J. (2000) Research on students' psychology and metal health condition. Higher Education Forum, 4, 40-44.

[4] Zhang, J.X., Weng, Z. and Liu, Q.G., et al (1995) A study on relationship between the depressive symptoms of the family members and the family function. Chinese Journal of Clinical Psychology, 3, 225-227.

[5] Liu, Y.N. and Jin, Y.L. (2001) A study on depression and related factors in undergraduates. Chinese Journal of Clinical Psychology, 3, 208-209.

[6] McKinney, C. H., Antoni, M.H., Kumar, M., Tim, F. C. and McCabe, P.M. (1997) Effects of guided imagery and music (GIM) therapy on mood and cortisol in healthy adults. Health Psychology, 16, 390-400. doi:10.1037/0278-6133.16.4.390

[7] Clair, A.A. and Memmott J. (2008) Therapeutic Uses of Music with Older Adults. 2th Edition, American Music Therapy Association, Maryland.

[8] Ashida, S. (2000) The effect of reminiscence music therapy sessions on changes in depressive symptoms in elderly persons with dementia. Annuals of Physical and Reha- bilitation Medicine, 52, 170-82.

[9] Schmid, W. and Aldridge, D. (2004) Active music therapy in the treatment of multiple sclerosis patients: A matched control study. Journal of Musical Therapy, 41, 225-40.

[10] Zhang, D.J. (2008) Integrated Research on the Mental Health and Its Education Among Chinese Adolescents. Journal of Southwest University, 34, 22-28.

[11] Wu, W.Y. (1990) Self-rating depression scale(SDS). Shanghai Archives of Psychiatry (Supplement of the new second Vol.): Assessment Scales in Psychiatry Series.

[12] Ji, J.L., Xia, Z.Y. and Xu, J.M. (1990) SCL-90 Assessment result analysis of college students of different majors. Chinese Mental Health Journal, 4, 123-125.

[13] Wang, X.D., Wang, X.L. and Ma, H. (1999) Rating Scales for Mental Health. Chinese Mental Health Press.

[14] Zung, W.K.K. (1986) Zung Self-rating Depression Scale and depression status inventory. In: Sartorius, N. and Ban, T.A. Eds., Assessment of Depression. Springer Verlag, Berlin, 22-231.

[15] Derogatis, L.R. (1975) How to use the systom distress checklist (SCL-90) in clinical evaluations, psychiatric rating scale. In: Derogatis, R.L. Ed., Self-Report Rating Scale, Hoffmann-La Roche Inc, 22-36.

[16] Guétin, S., Soua, B., Voiriot, G., Picot, M.C. and Hérisson, C. (2009) The effect of music therapy on mood and anxiety-depression: An observational study in insti- tutionalised patients with traumatic brain injury. Annals of Physical and Rehabilitation Medicine, 52, 30-40. doi:10.1016/j.annrmp.2008.08.009

[17] Erkkilä, J., Gold, C., Fachner, J., Ala-Ruona, E., Punkanen, M. and Vanhala, M. (2008) The effect of improvisational music therapy on the treatment of depression: Protocol for a randomised controlled trial. BioMed Central Psychiatry, 8, 1-9.

[18] Castillo-Pérez, S., Gómez-Pérez, V., Velasco, M.C., Pérez-Campos, E. and Mayoral, M.A. (2010) Effects of music therapy on depression compared with psycho- 
therapy. Arts in Psychotherapy, 37, 387-390. doi:10.1016/j.aip.2010.07.001

[19] Chang, M.Y., Chen, C.H. and Huang, K.F. (2008) Effects of music therapy on psychological health of women during pregnancy. Journal of Clinical Nursing, 17, 2580-2587. doi:10.1111/j.1365-2702.2007.02064.X
[20] Choi, A.N., Lee, M.S. and Hyun, H.J. (2008) Effects of group music intervention on depression, anxiety, and relation- ships in psychiatric patients: A pilot study. Journal of Alternative \& Complementary Medicine, 14, 567-570. doi:10.1089/acm.2008.0006 